\title{
LA ANTIPOESIA ENTRE EL NEOVANGUARDISMO Y LA POSMODERNIDAD
}

POR

ALVARO SALVADOR

Universidad de Granada

La poesía morirá si no se la ofende

(Nicanor Parra)

\section{NICANOR PARRA ¿ANTIPOETA Y MAGO?}

Con la perspectiva que nos proporcionan los casi cuarenta años transcurridos desde la aparición de Poemas y antipoemas (1954), podemos atrevernos a exponer si no la esencia misma, la lógica interna del discurso antipoético, sí al menos el lugar teórico que ocupa en la actualidad y su disposición en la cartografía cognoscitiva de la historia literaria más reciente. De cualquier modo, las últimas incorporaciones críticas que en la década recién concluida han llenado nuestros estantes metodológicos con un cierto aire renovador cuando no mesiánico, quizá puedan sernos hoy muy útiles a la hora de desentrañar algunos aspectos no demasiado esclarecidos por anteriores aproximaciones al objeto de estudio que ahora proponemos.

Y si adelanto esta advertencia a modo de introducción no es sólo por la parte que personalmente me concierne, esto es, la revisión crítica que yo mismo efectúo sobre cierto texto de juventud dedicado a los misterios de la "antipoesía" que un día tuve la osadía de publicar, sino porque considero a la luz del nuevo acercamiento realizado para ordenar estas páginas que las aportaciones acumuladas en estos úl timos quince años no son ni muy numerosas, ni demasiado esclarecedoras a la hora de resolver los problemas con los que ya entonces tuve que enfrentarme.

¿Qué es, pues, la antipoesía? En 1958, afirmaba el propio Parra: "el antipoema que, a la postre, no es otra cosa que el poema tradicional enriquecido con la savia surrealista - surrealismo criollo o como queráis llamarlo-, debe aún ser resuelto desde el punto de vista psicológico del país y del continente a que pertenecemos, para que pueda ser considerado como un verdadero ideal poético" ${ }^{\prime 1}$ ¿Es, entonces, la antipoesía un ideal poético? ¿Un ideal que persiguió, como persigue Parra? ¿Cómo puede ser o llegar a ser un ideal algo que se declara a priori como anti, y por lo tanto como lo opuesto al ideal poético?

\footnotetext{
${ }^{1}$ Nicanor Parra, Entrevista en Atenea, Concepción, núms. 380-381, 46-48.
} 
Está claro, -y la crítica tradicionalmente lo ha visto con meridiana lucidez (Alegría, Benedetti, Retamar, De Costa, Schopf, etc.)-que ese anti no se dirige únicamente a un objetivo tan abstracto como pueda ser el "ideal poético" en general, sino que está, por una parte, fechado en tanto en cuanto Parra y su proyecto pertenecen a un momento histórico concreto en el desarrollo del discurso poético general, así como a una coyuntura específica dentro del discurso poético chileno en particular. Discurso poético, el chileno, tan enormemente significativo en el desarrollo de la poesía hispanoamericana del presente siglo. Por otra parte los textos de Parra nos dicen muy a las claras contra qué escrituras poéticas quieren ellos ser poemas. Bástenos con algunos ejemplos:

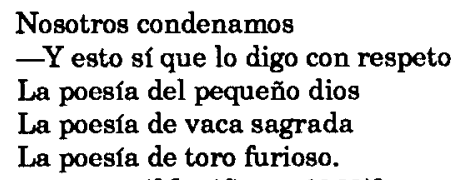

(Manifiesto, 1969) $^{2}$

Los referentes están claros: Huidobro, Neruda, Rokha, como en otros lugares estará también Gabriela Mistral $^{3}$ e incluso las referencias a la tradición hispánica más general, al neopopularismo canonizado en la obra de Alberti y Lorca4:

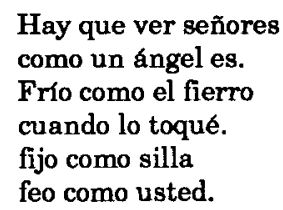

(Sinfonta de Cuna)

Parra, pues, define su escritura a la contra de lo que podríamos entender como "norma poética hegemónica" en el momento histórico en que pretende inaugurarse a sí mismo como poeta. No obstante, esta definición nos lleva nuevamente, aunque apretando una tuerca distinta, a la contradicción que percibíamos más arriba. ¿Cómo puede atacarse desde la iconoclastia a un discurso poético que

\footnotetext{
${ }^{2}$ Nicanor Parra, Chistes para desorientar a la poesta. Antología al cuidado de Nieves Alonso y G. Triviño, Madrid: Visor, 1989; Antipoemas. Antología de J. M. Ibáñez Langlois, Barcelona: Seix-Barral, 1972 y Obra gruesa, Santiago de Chile, Nascimento, 1969.

${ }^{3}$ René de Costa, "Para una poética de la (anti)poesía", introducción a Nicanor Parra, Poemas y antipoemas, Madrid: Cátedra, 1988, 24-29.

4 de Costa, 24.
} 
fundó su razón de ser en el hecho de construirse a sí mismo como ruptura radical con el pasado? Y lo que es más importante ¿cómo el corpus surgido de los movimientos de vanguardia hispanoamericanos llega a convertirse en norma poética hegemónica? Quizá en este punto esté la clave de la problemática estética definida como antipoesía, de la lógica interna de sus textos.

Veamos cómo el propio Nicanor Parra plantea la problemática en un texto, a mi juicio, mucho más significativo que los que se citan habitualmente. Habla Parra en una carta dirigida a Tomás Lago:

La poesía egocéntrica de nuestros antepasados en que ellos tratan de demostrar al lector cuán estimable es el ser humano, cuán inteligentes y sensibles son ellos mismos, cuán dignos de admiración son los objetos de este mundo, debe ceder el paso a una poesía más objetiva de simple descripción de la naturaleza del hombre. Hasta cuándo seguimos echándonos tierra a los ojos. El bohemio pálido y emocionado debe quemar su sombrero de una vez por todas; el individuo no tiene importancia en la poesía moderna sino como un objeto de análisis psicologico; hablando en términos muy generales nuestros poéticos [sic] románticos son cantores de b́pera, buenos, malos o excelentes a veces, geniales algunos como nuestro común amigo Pablo, pero de todas maneras gentes que poseen una noción restringida y finiquitada del trabajo artístico. Los más despejados de ellos creyeron haber terminado con el "cisne de nevado plumaje, pero en realidad no es asi. La generacion anterior a nosotros no hizo otra cosa que terminar con el argumento convencional en la poesía, con la anécdota, sin preocuparse de revisar los principios mismos de la ciencia poética. Ellos se conformaron con lograr los mismos resultados que nuestros antecesores aunque con medios diferentes. La solemnidad y la gravedad dogmática del arte del siglo XIX siguió viva en ellos a pesar de las enseñanzas de Picasso y de Dalí. Me parece que el arte no puede ser otra cosa que la reproducción objetiva de una realidad psicológica, y ese fin no se consigue tratando de mostrar soblo aquello que se considera rebestido (sic) de cierta dignidad. Un poema debe ser una especie de corte practicado en la totalidad del ser humano, en el cual se vean todos los hilos y todos los nervios, las fibras musculares y los huesos, las arterias y las venas, los pensamientos, las imágenes y las sensaciones, etc, etc, no se trata de preparar un pastel más o menos fácil de tragar, estoy en contra de los tristes y los angustiados, de la misma forma que estoy en contra de los bu fones, estilo Huidobro. También me rebelo en contra de los profetas y en contra de los pensadores proféticos estilo T. S. Eliot. Estoy convencido de que el poeta no tiene derecho de interpretar sino simplemente de describir fríamente; el debe ser un ojo que mira a través de un microscopio en cuyo extremo pulula u na fauna microbiana; un ojo capaz de explicar lo que ve, eso es aproximadamente el asunto ...5.

La carta está fechada en Oxford, 3 de Noviembre de 1949. En ella podemos apreciar la particular descripción de las aporías de la vanguardia que realiza Parra. No tenemos aquí espacio suficiente como para detenernos en la prolija

5 de Costa, 91. 
exposición de dicha problemática, pero podemos afirmar que, paradójicamente, desde una perspectiva "radicalmente vanguardista" - entendido el término en su sentido más profundamente revolucionario-Parra tiene razón. A grandes rasgos, el "metaforismo revolucionario" que caracterizó la primera hora de los grandes poetas hispanoamericanos del siglo XX acabó convirtiéndose en el "gran discurso analógico" del mundo contemporáneo; el "surrealismo emancipador" en la legitimación de un estructuralismoetnológico y sacralizante. Quizá de todos los antis que veíamos más arriba, el nunca explícito anti-Paz sea desde la perspectiva actual el ingrediente más lleno de contenido y con un sentido histórico más claro que pueda definir a una posible antipoesía. Lo decía Pedro Gimferrer el otro día en una entrevista: "Paz quizá sea, a mi juicio, el único representante que queda de la 'poesía', de la verdadera poesia".

La reacción de Parra, por lo tanto, desde una perspectiva renovadora que quiere ser continuadora, además, de los auténticos principios de renovación artística que presidieron la inauguración de un siglo lleno de avances científicos y guerras terribles, es perfectamente lógica y no demasiado excepcional.

\section{LA INFLEXIÓN DE LOS AÑOS CINCUENTA}

Es ya un lugar común generalmente admitido el afirmar que en torno a los años cincuenta y principios de los sesenta de nuestro siglo se produce una inflexión ideológica evidenciada de un modo muy radical no sólo en las manifestaciones artísticas sino en los cambios de valores morales, sociales e incluso doméstico cotidianos. Inflexión que, sin duda, no es más que la manifestación externa de otros cambios más profundos que por entonces se operan en el seno de nuestras sociedades y que suelen definirse como el nacimiento de la llamada "sociedad de consumo", surgida de la etapa posbélica, el nacimiento de un nuevo orden político de "bloques" y de un nuevo imperialismo militar e ideológico. Es la etapa que Mendel definió como "fase del capital multinacional" y que se extendería hasta nuestros días.

En cuanto al orden de lo literario, también parece un lugar común el acuerdo de que por esos años surgen en distintos lugares del mundo occidental -tengamos en cuenta que en la mayoría de los países hispanoamericanos se goza por entonces un período de relativa estabilidad política y de notable desarrollo económico- una serie de propuestas estéticas que coinciden fundamentalmente en dos aspectos que me parecen enormemente significativos:

1. Un interés por "rehumanizar los discursos", esto es por acercarlos a la sensibilidad general, al inconsciente colectivo, a la vida de la comunidad, a través de recursos estilísticos que funcionen como elementos tendientes a romper la distancia tradicional entre la solemnidad del arte y el hombre de la calle.

${ }^{6}$ Ernst Mendel, El capitalismo tardio, México: Era, 1972. 
2. Un interés por la recuperación de ciertos valores que los movimientos históricos de vanguardia pusieron en funcionamiento, destacandoentre éstos la necesidad de un arte, al menos, "subversivo", es decir, un arte que se identifique con la vieja utopía de cambiar la vida.

Conviene aclarar que no siempre estos dos rasgos coinciden en un mismo movimiento artístico, sobre todo a partir de ese momento coyuntural que simboliza el "Mayo del 68", pero sí es cierto que el tono general de renovación, desde la llamada "Generación del 50" hispánica a la "Beat Generation" norteamericana, presencia de los dos rasgos señalados.

José Emilio Pacheco, en un artículo titulado "Notas sobre la otra vanguardia”, defendía la existencia de dos vanguardias: una heredera de la tradición europea, la otra latinoamericana con cierta referencia estadounidense, encarnada en loque después pasó a llamarse "antipoesía" o también "poesía conversacional" . Pacheco sitúa el comienzo de esta segunda línea en el tiempo mismo de la vanguardia clásica, es decir en el año de publicación de la New Poetry (1922), puesto que Salvador Novo publicará su Antología de la poesía moderna norteamericana en 1924.

De cualquier modo, parece más razonable pensar, como hacen otros muchos críticos, entre ellos Jitrik, que la influencia de los planteamientos poéticos norteamericanos sea más tardía y "que el coloquialismo poético de Nicanor Parra sí tenga esa fuente ${ }^{m 8}$. Pienso que el intento por fijar el comienzo de la influencia de la poesía norteamericana en la hispanoamericana a partir de esta problemática, teniendo además en cuenta la confusión que introduce el diferente significado del término modernismo en ambosidiomas, es un problema vano. Lo importante para el momento histórico y para los planteamientos estéticos a que nos estamos refiriendo es la influencia "en si". Porque el intento por conseguir una poesía de tono moderado, conversacional, cercano al "habla" de los lectores, que escenifique y represente las experiencias del hombre común, pero trascendiéndolas como si se trataran de experiencias únicas oirrepetibles, es un viejo proyecto de toda la tradición anglosajona desde Wordsworth a Eliot o Auden, como señaló Robert Langbaun en su The Poetry of Experience ${ }^{9}$. La formación anglosajona de algunos de los más importantes escritores hispánicos de este momento, incluido el propio Parra, es sobradamente conocida: Alberto Girri, Jaime Gil de Biedma, el propio Pacheco, etc. En un artículo que sería magnífico si no fuera por el marcado tono "programático" con el que se reviste a la hora de sacar conclusiones, Fernández Retamar traza muy lúcidamente el camino de la "poesía conversacional" en lengua castellana, conectándola con la

\footnotetext{
${ }^{7}$ En Revista Iberoamericana 106-107, Pittsburgh, enero-junio de 1979, 327-334.

${ }^{8}$ Noé Jitrik, "Notas sobre la vanguardia latinoamericana", en La vibración del presente, México: F.C.E., 1987, 61.

${ }^{9}$ R. Langbaun, The Poetry of Experience, New York: Norton, 1963.
} 
tradición anglosajona a través de una pista clásica: la que le proporciona Cernuda en su estudio sobre Campoamor ${ }^{10}$.

No obstante, la antipoesía no consiste únicamente en adoptar un tono conversacional, unas palabras de familia o el vocerío de la plaza pública. La antipoesía consiste también en la incorporación de la "savia surrealista" que deje al hombre abierto en canal sobre la mesa de disecciones. Intento que tampoco es exclusivo de la tradición vanguardista latinoamericana, aunque sea tardía. Jacques Prévert en Francia con sus Paroles, Hans Magnus Enzengsberger en Alemania con sus Poesías para los que no leen poesías e incluso nuestra Gloria Fuertes, inmersa en el posvanguardismo "postista", constituirían algunos ejemplos de proyectos poéticos muy cercanos al de nuestro poeta chileno.

\section{MARQUE CON UNA CRUZ LA DEFINICIÓN QUE CONSIDERE CORRECTA.}

¿Qué es la antipoesía?: ¿Un temporal en una taza de té? ¿Una mancha de nieve en una roca? ¿Un espejo que dice la verdad? ¿Un bofetón al rostro del Presidente de la Sociedad de Escritores? ¿Un ataúd a chorro? ¿Un ataúd a fuerza centrífuga? ¿Un ataúd a gas de parafina? ¿Una capilla ardiente sin difunto?" Son algunas de las repuestas posibles que Parra nos invita a señalar en su poema "Test". Poema que funciona ateniéndose claramente a los principios que el mismo Parra tenía ya bastante perfilados en 1949: "el poema como representación objetiva de una realidad psicológica". El poema va reproduciendo objetivamente una realidad psicológica, la "antipoesía", al proponerla como resultado de la levitación continua de la interrogante sobre aquellos aspectos de la realidad que, indudablemente, no son la antipoesía, pero que además se articulan como resultado de los mismos efectos que produce la antipoesía al asociar aspectos de la realidad que en lógica racional no tienen nada que ver entre sí. Estos versos no son exactamente metáforas; a veces paradojas, frases hechas, discursos extraliterarios, slogans, delirios, etc., etc., aunque todos tienen algo en común: la yuxtaposición de elementos que no guardan ninguna relación. Es decir, la asociación libre e inconsciente de objetos pertenecientes a la realidad y distantes entre sí en su materialidad o su sentido.

Aquí podríamos identificar el ingrediente surrealista que Parra reclama para su poesía. Como él mismo decía en la carta citada, "el individuo no tiene importancia en la poesía moderna sino como un objeto de análisis psicológico". Es decir, el "sujeto" ya no es el ente compacto, fuerte, sin fisuras que a lo largo de siglo XIX va imponiendo su ley sobre la naturaleza recién conquistada. La racionalidad ha dejado al descubierto sus trapos sucios diseccionada por la ciencia psicológica y psicoanalítica. El sujeto se presenta como una realidad "fragmentaria" en la que la irracionalidad tiene su propio peso específico:

${ }^{10}$ R. Fernández Retamar, "Antipoesía y poesía conversacional en América Latina”, en Panorama actual de la literatura latinoamericana, Madrid: Fundamentos, 1971, 331 347. 


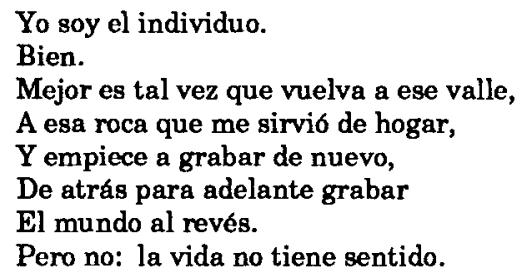

(Soliloquio del individuo)

Ahora bien, Parra tampoco es un mago, y en ese sentido no puede considerarse surrealista à la page, ni siquiera surrealista criollo como él se define en algún momento. El surrealismo criollo -y tendríamos que volver a citar aquí a $\mathrm{Paz}-$ es fundamentalmente mágico: todo el componente pre-científico, esotérico, trascendente, que Breton y sus muchachos introdujeron en las prácticas pseudo-psicoanalíticas, encontró un caldo de cultivo suficientemente abonado en esa "realidad superior" que significa el "estructuralismo etnológico analógico" practicado por Paz y sus seguidores. De tal modo que la poesía ha sido devuelta por ellos al lugar que nunca debió abandonar: el ámbito de lo sagrado anterior a la aparición de la estética vanguardista, es decir, pre-científico.

Parra, en cambio, es un matemático. Si le interesa la interpretación del hombre que efectúa la psicología, es precisamente porque no se trata de interpretación sino de análisis científico. Yel mismo, o parecido, procedimiento, como hemos visto, es el que propugna para la poesia. Parra no es un mago, sino más bien un "prestidigitador". Parra construye sus tinglados poéticos, sus antipoemas, sus artefactos, con plena conciencia de que son productos artificiales, productos del hombre, pero artificiales. Esa artificialidad, es posible que tenga que sostenerse en un sistema analógico, pero ese sistema analógico no abre las puertas de una "realidad superior" o "trascendente", ese sistema analógico no es el artificio que tradicionalmente se construyó acudiendo a la tradición mítica y religiosa, hermosas mentiras, pero mentiras al fin y al cabo. A Parra, en todo caso, le interesa construir un sistema analógico nuevo pero que esté directamente relacionado con los "vicios del mundo moderno":

Los vicios del mundo moderno:

El automovil y el cine sonoro,

Las discriminaciones raciales,

El exterminio de los pieles rojas,

Los trucos de la alta banca,

La catástrofe de los ancianos,

....

El mundo moderno es una gran cloaca:

Los restoranes de lujo están atestados de cadáveres digestivos.

Eso no es todo: los hospitales están llenos de impostores, .... 
Tratemos de ser felices, recomiendo yo, chupando la miserable / costilla humana.

La suerte está echada.

Aspiremos este perfume enervador y destructor

Y vivamos un día más la vida de los elegidos:

....

Por todo lo cual

Cultivo un piojo en mi corbata

Y sonrío a los imbéciles que bajan de los árboles.

(Los vicios del mundo moderno)

Un sistema analógico, por tanto, que tiene que ver más con lo absurdo que con la bondadosa y utópica creencia en una primitiva "harmonía" universal, realidad superior que el hombre debe esforzarse en recuperar por medio de la magia poética. La poesía de Parra es una poesía implacable que nos pone una y otra vez contra las cuerdas, acosándonos con los golpes de la miseria e irracionalidad de la condición humana.

En cierto modo, la lucidez de Parra es parecida a la de Borges, sólo que el primero actúa cínicamente en sus escritos, mientras que el segundo actúa con sinceridad, es decir, con humanismo. El nuevo artificio surgido del absurdo del mundo moderno debe tener una utilidad para el hombre. Como señala Julio Ortega, "cuando Parra dice la vida no tiene sentido es claro que lo dice desde el absurdo hallado, y que este encuentro es precisamente contra el sinsentido de la vida; o sea la búsqueda de otro sentido para ella: búsqueda amarga y sarcástica, hecha de humor y fantasía, de rigor y de patetismo"11. Humor y sarcasmo que actúan como recursos subversivos, dinamitando otra de las constantes tradicionales de la poesía moderna: la ironía. Porque Nicanor Parra no ironiza, no proyecta su inteligencia superior para establecer una distancia entre la realidad y el mundo privilegiado de la creación sublime, -como hará Borges, por ejemplo, ironizando al utilizar el sistema analógico como si fuese una verdad, pero desde la conciencia plena de su artificialidad-Parra "ridiculiza" la realidad al mostrarla como un absurdo que se cree lógico, y ridiculiza la poesía al presentarla como discurso "sublime" de esa realidad. Y, por supuesto, se ridiculiza, ridiculiza al antipoeta:

Ni muy listo ni tonto de remate

Fui lo que Fui: una mezcla

De vinagre $y$ aceite de comer

¡Un embutido de ángel y bestia!

(Epitafio)

11 "Sobre la poesía de Nicanor Parra", en Figuración de la persona, Barcelona: Edhasa, $1971,260$. 
Parra no pretende en ningín momento que su antipoesía contenga la verdad, ni siquiera una verdad parcial, simplemente la pone ahí como un producto más de la inseguridad, de la fragmentación, de la falta de valores profundos, de la duda, de la condición del hombre del siglo XX:

Antes de despedirme

Tengo derecho a un último deseo:

Generoso lector

quema este libro

No representa lo que quise decir

A pesar de que fue escrito con sangre

No representa lo que quise decir.

(Me retracto de todo lo dicho)

\section{LA ANTIPOESIA EN EL OCASO DE LA MODERNIDAD.}

¿Pertenece, entonces, la antipoesía a ese corpus de producciones artísticas surgidas en torno a la dinámica de los años sesenta y que han dado en llamarse "neovanguardia"?

Veamos en primer lugar qué sentido puede tener en la actualidad el término neovanguardia. Decía Peter Bürger que "la neovanguardia institucionaliza la vanguardia como arte y niega así las genuinas intenciones vanguardistas", porque "en tanto que el medio con cuya ayuda esperan alcanzar los vanguardistas la superación del arte ha obtenido con el tiempo el status de obra de arte, su aplicación ya no puede ser vinculada legítimamente con la renovación de la praxis vital"12. Esto es, cualquier intento vanguardista que pretenda producir en la actualidad un efecto parecido al que intentaron llevar a cabo las vanguardias históricas está condenado al fracaso, porque la estética de nuestro tiempo se caracteriza por la restauración de la categoría clásica de la obra artística y por la aplicación con fines artísticos de los procedimientos que la vanguardia ideó con intención "antiartística".

No obstante, como hemos visto en el caso de Parra, hay proyectos artísticos que mantienen su carácter antinormativo desde su propia lógica interna y con una lucidez y efectividad verdaderamente admirables. Son proyectos que, sin duda, se mueven en un terreno sumamente resbaladizo y en un momento histórico bastante problemático. Momento que, como sabemos y hemos visto, se define en términos de "neovanguardia", "rehumanización", "último momento de la utopía" y, más recientemente, "final de la modernidad".

Casi todos los teóricos de la llamada "posmodernidad" coinciden en fechar el nacimiento de este período histórico en la década de los años cincuenta y

${ }^{12}$ Peter Bürger, Teorla de la vanguardia, Barcelona: Península, 1987. 
principios de la de los sesenta ${ }^{13}$. Precisamente la restauración del concepto de obra artística moderna, englobando en el mismo la práctica vanguardística, señalaría el momento de corte, de ruptura con la modernidad. Jameson defiende la tesis de que "estas actitudes (las vanguardias, modernistas en el ámbito anglosajón) se han vuelto arcaicas debido a una mutación en la esfera de la cultura. No solamente Picasso y Joyce han dejado de ser repugnantes, sino que ahora los encontramos, en conjunto, bastante "realistas". Lo que no es sino el resultado de la canonización e intitucionalización académica del movimiento modernista en general, que puede fecharse al final de la década de los años cincuenta"14.

Si aceptamos este corte, si aceptamos la existencia de un espacio posmoderno, tal y como lo entiende Jameson, en el que van apareciendo una serie de producciones artísticas marcadas por la heterogeneidad, podremos apreciar inmediatamente una serie de coincidencias, de planteamientos comunes, de rasgos similares, entre la antipoesía y lo que ha dado en llamarse "estética de la posmodernidad".

En primer lugar, ya hemos visto cómo para Parra la antigua homogeneidad del sujeto no es más que pura fragmentación, objeto psicológico descentrado. El posmodernismo representaría el fin de este proceso que se inicia con las vanguardias y en el que la subjetividad se diluye hasta el punto de poder hablar de un ocaso de los afectos. El fin del yo burgués significa también el fin de los estilos individualizados, de los "poéticos románticos" como diría Parra, el fin de los sentimientos entendidos como liberaciones de una trascendencia y que se manifiestan ahora como "intensidades" que se asocian libremente en una especie de euforia próxima a la que se produce en la esquizofrenia:

\author{
La madre de un hombre está gravemente enferma \\ Parte en busca del médico \\ Llora \\ En la calle ve a su mujer acompañada de otro hombre \\ Van tomados de la mano \\ Los sigue a corta distancia \\ De árbol en árbol \\ Llora
}

\footnotetext{
${ }^{13}$ Andreas Huyssen, "En busca de la tradicion: vanguardia y posmodernismo en los años $70^{n}$ en Modernidad y postmodernidad, ed. de Josep Pico, Madrid: Alianza, 1988; Irving Howe, "Mass Society and Posmodernism Fiction", en The Decline of the New, New York 1970, 190-207; Richard Howard, Alone with America. Essays of the Art of Poetry in the United States since 1950, New York: Atheneum, 1971; Matel Calinescu, "On Postmodernism", en Five Faces of Modernity, Durham: Duke University Press, 1987, 265-312, etc., etc.

${ }^{14}$ Frederic Jameson, El posmodernismo o la logica cultural del capitalismo avanzado, Barcelona: Paidós, 1991.
} 


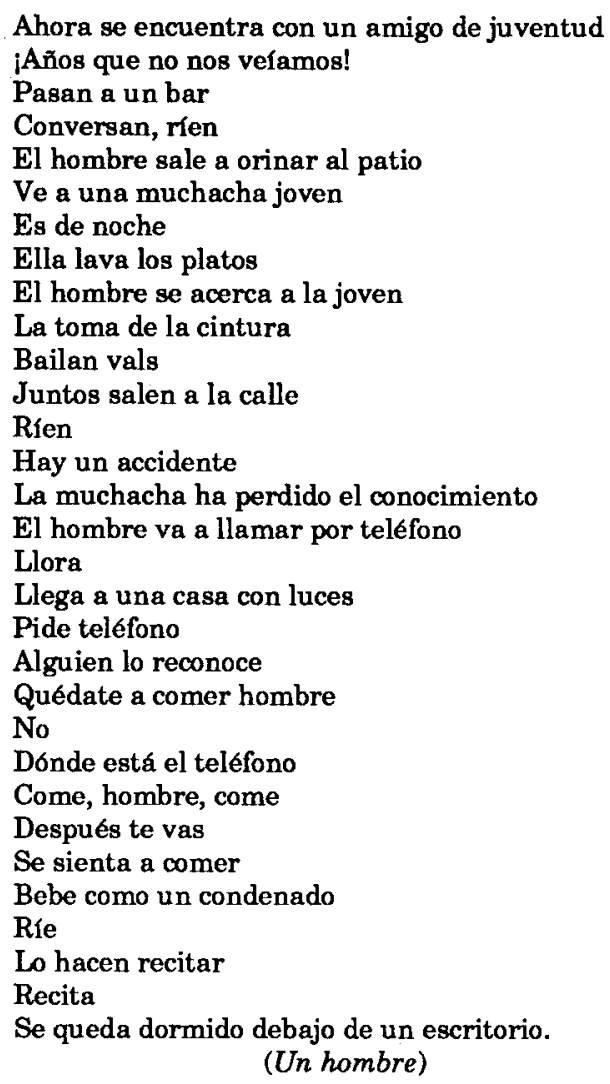

Podemos hablar en este poema de escritura esquizofrénica en el sentido lacaniano, es decir, como una ruptura en la cadena significante, en la trabación sintagmática de esa serie de significantes que constituye una aserción o un significado. La ruptura de la cadena significante elimina la percepción de la temporalidad. Si no puede unirse el pasado el presente y futuro de la frase, tampoco puede unificarse la percepción temporal de la propia experiencia biográfica de la vida psíquica. El poema queda reducido a una serie de meros presentes carentes de toda relación con el tiempo, transmitidos con una rara "intensidad", llena de cargas de afectividad, esporádicas y no relacionadas. El carácter temporal de la narración clásica o moderna desaparece o se diluye ostensiblemente. Es lo que podríamos llamar un ejercicio de discontinuidades.

Muchos otros rasgos delllamadoespacio poético posmoderno están presentes en la antipoesía y podríamos rastrearlos si el espacio y la ocasión lo permitieran. De cualquier modo, afirmar taxativamente que Parra es un poeta "posmoderno" 
y que la antipoesía pertenece a esta estética es, cuanto menos, arriesgado. No pretendemos parecernos a esos críticos receteros que van modificando su librillo según sentencia del tiempo y la moda. Pero la crítica de la "posmodernidad" nos parece un espacio teórico lo suficientemente serio y sugerente como para abordarlo con interés y rigor. Y, sobre todo, quizá su terapia pueda sernos muy útil para intentar comprender algunos fenómenos fronterizos, como éste de la antipoesía, difícilmente identificables.

La crítica más seria que puede hacerse a la posible "posmodernidad" de la antipoesía quizá sea la constatación de su sentido "crítico" y su vocación humanista, sobre todo si recordamos los famosos "Cuatro sonetos del Apocalipsis". Entramos aquí, sin duda, en una problemática más general que enfrenta la categoría crítica de "posmodernidad" con el ámbito tercermundista de lo latinoamericano. No obstante, soy partidario de no olvidar lo que un sistema de colonización cultural puede llegar a producir como efecto precisamente de las contradicciones ideológicas que implica -baste con recordar casos "modernos" como los de Darío o Borges. No es éste tampoco el lugar más adecuado para resolver esta problemática, pero me gustaria adelantar que indudablemente el "espacio hispanoamericano" no es, hoy por hoy, un espacio posmoderno, pero eso no implica que algunos de los fenómenos y manifestaciones de lo posmoderno no puedan moverse por ese espacio. Sobre todo si lo hace, y con toda soltura, el capitalismo multinacional.

Expongamos un ejemplo final: existe un poema de Parra, uno de sus "artefactos", modalidad estética que se mueve muy cerca de lo fragmentario posmoderno, que reza lo siguiente:

\section{USA \\ DONDE LA LIBERTAD \\ ES UNA ESTATUA}

Así leído, como un "grafitti", el poema segrega una indudable carga crítica, una acusación subliminal: la libertad en Estados Unidos se limita a ser una estatua. Sin embargo, este poema, convertido en poema concreto, proyectado en una pantalla en mitad de Times Square y además traducido del siguiente modo: USA/ WHERE/ LIBERTY/ e "imagen" de la estatua archiconocida que ostenta dicho nombre, se vacía de sentido crítico. Queda convertido en uno de esos objetos ornamentales de significado ambiguo y contenido vacío, arte espacial sin mensaje y sin hombre debajo, como una constatación que se mira a sí misma. La antipoesia es entonces un simulacro de poesía que quiere ser poesía no siendo "poesía". 